\title{
Fluorine F 18 Fluoro Furanyl Norprogesterone
}

\author{
National Cancer Institute
}

\section{Source}

National Cancer Institute. Fluorine F18 Fluoro Furanyl Norprogesterone. NCI Thesaurus. Code C88263.

The progesterone derivative fluoro furanyl norprogesterone (FFNP), radiolabeled with fluorine $F 18$, with positron-emitting radiolig and activity. Upon injection, fluorine $F 18$ fluoro furanyl norprogesterone (F18-FFNP) binds to progesterone receptors (PgR) in progesterone-responsive tissues. In PgR-positive breast cancer, positron emission tomography (PET) may then be used to quantitate hormone receptor status. 